\title{
BMJ Open Impact of night and shift work on metabolic syndrome and its components: a cross-sectional study in an active middle-to-older-aged population-based sample
}

\author{
Virginie Bayon, ${ }^{1}$ Mathieu Berger (10 , ${ }^{1}$ Geoffroy Solelhac (1) ,, José Haba-Rubio, ${ }^{1}$ \\ Pedro Marques-Vidal, ${ }^{2}$ Marie-Pierre Strippoli, ${ }^{3}$ Martin Preisig, ${ }^{3}$ Damien Leger, ${ }^{4,5}$ \\ Raphael Heinzer ${ }^{1}$
}

To cite: Bayon V, Berger M, Solelhac G, et al. Impact of night and shift work on metabolic syndrome and its components: a cross-sectional study in an active middleto-older-aged populationbased sample. BMJ Open 2022;12:e053591. doi:10.1136/ bmjopen-2021-053591

- Prepublication history and additional supplemental material for this paper are available online. To view these files, please visit the journal online (http://dx.doi.org/10.1136/ bmjopen-2021-053591).

VB and MB contributed equally.

VB and $M B$ are joint first authors.

Received 20 May 2021 Accepted 24 January 2022

Check for updates

(C) Author(s) (or their employer(s)) 2022. Re-use permitted under CC BY. Published by BMJ.

For numbered affiliations see end of article.

Correspondence to Dr Mathieu Berger; mathieuberger@outlook.com

\section{ABSTRACT}

Objectives To examine the effects of work schedules on metabolic syndrome and its components in active middleto-older-aged workers.

Methods A cross-sectional analysis including middleto-older-aged active workers from the population-based CoLaus|PsyCoLaus study (Lausanne, Switzerland) was performed. Work schedule was self-reported and defined as follows: permanent day, day shift, night shift and permanent night work. Associations between work schedule and the risk of metabolic syndrome and its components were analysed using multivariable-adjusted logistic regressions.

Results A total of 2301 active workers (median age (IQR): 55.4 (50.8 to 60.4 ), $50.1 \%$ women) were included. Of these, 1905 were permanent day workers, 220 were dayshift workers, 134 were night-shift workers and 42 were permanent night-shift workers. There were significant interactions between sex and work schedule for metabolic syndrome, high triglycerides and visceral obesity. Men but not women permanent night workers had a higher prevalence of metabolic syndrome than permanent day workers in multivariable-adjusted analyses (OR 4.45 (95\% Cl 1.36 to 14.56)). Analysis of metabolic syndrome subcomponents showed that the association between work schedule and metabolic syndrome in men was mainly driven by visceral obesity (OR 3.35 (95\% Cl 1.04 to 10.76)). Conversely, women but not men working in night shift were at increased risk of having high triglycerides compared with permanent day workers (OR $2.92(95 \% \mathrm{Cl}$ 1.03 to 8.27)).

Conclusions The risk of metabolic syndrome is higher in men working in permanent night shift compared with permanent day work, and this association could be mediated by visceral obesity.

\section{INTRODUCTION}

Due to economic constraints, efficiency needs or performance objectives, night and shift work $(3 \times 8)$ has become highly prevalent in modern societies. Approximately, $18 \%$ of all
Strengths and limitations of this study

- This study evaluated the effects of work schedules on metabolic syndrome and its subcomponent in a middle-to-older-aged general population setting with a precise and extensive assessment of cardiometabolic phenotypes.

- The association between different shift work schedules and metabolic syndrome was assessed after adjustment for multiple cofounders.

- Because the primary aim of the cohort was not to evaluate the impact of shift work, no precise characterisation of workstations and work rhythms (hourly amplitude, direction of rotation, duration of rotations and duration of exposition) was performed.

- A 'healthy worker effect' with a selection of 'night shift tolerant' workers cannot be ruled out given the older age of our sample.

European workers work in shifts, and this rate is as high as $35 \%$ in some countries. ${ }^{1}$ Nonstandard working schedules (eg, shift work, night work) are no longer limited to health and safety workers but are spread across all industries and services, from manufacturing, to transport, telecommunications and more.

Night and shift work interfere with the physiological circadian rhythm, desynchronising the biological clock, which can favour systemic inflammation. ${ }^{2}$ Night and shift works are also associated with reduced and disturbed sleep. ${ }^{3}$ Hence, both circadian disruption and short or poor sleep could be mediators explaining the relationship between night or shift work and chronic health conditions, including increased risk of cardiovascular and metabolic disorders. ${ }^{4}$ Moreover, several laboratory-controlled studies showed that circadian rhythm desynchronisation and 
sleep restriction have detrimental effects on neuroendocrine, inflammatory and immune functions. ${ }^{5}$

The health-related impact of atypical work schedules has, thus, been a topic of interest for some time. ${ }^{6}$ Sleep disturbances, decreased vigilance and increased risk of accidents are among the recognised short-term negative effects of night and shift work. ${ }^{7}$ Longer term health effects have also been described and include increased risk of cardiovascular and metabolic disorders. ${ }^{89}$ However, the impact of shift work on metabolic syndrome is not yet completely understood, particularly in the middle-toolder-aged population of workers though it is well established that the cardiometabolic risk gradually increases with advancing age.

Metabolic syndrome combines several interrelated metabolic risk factors associated with all-cause mortality. ${ }^{10}$ Subjects with metabolic syndrome have a higher risk of cardiovascular disease mortality and morbidity. ${ }^{11}$ Metabolic syndrome definition is based on five components: high blood pressure (BP), hyperglycaemic, high triglycerides, low-high-density lipoprotein (HDL) cholesterol and visceral obesity. A higher prevalence of metabolic syndrome and its components among night and shift workers has previously been suggested in some studies. ${ }^{12}{ }^{13}$ However, the specific effect of shift work and permanent night work remains largely unknown. Moreover, a recent systematic review concluded that there was insufficient evidence regarding the association between shift work and metabolic syndrome when confounding variables are taken into account. ${ }^{14}$

Thus, using data of active middle-to-older-aged workers from a population-based study, the aim of the present paper was to assess the cross-sectional association between metabolic syndrome and its components according to four types of work schedules (permanent day, day shift, night shift and permanent night-shift work).

\section{METHODS}

\section{Study design}

Cross-sectional analysis of a population-based cohort study.

\section{Population}

CoLausIPsyCoLaus is a population-based cohort exploring the biological, genetic and environmental determinants of cardiovascular risk factors, cardiovascular diseases and mental disorders in the middle-to-older-aged population of Lausanne, Switzerland. The methodological aspects (participant recruitment and follow-up) have been previously reported. ${ }^{15}$ Briefly, a simple, non-stratified, random sample of 6734 subjects from the Lausanne population aged 35-75 years was recruited between 2003 and 2006. The baseline and three follow-up evaluations included physical and psychiatric examinations, blood sampling and self-completed questionnaires. All data analysed in the present paper were obtained from the second physical follow-up evaluation $(n=4881)$, which took place between 2014 and 2017.

\section{Patient and public involvement}

No patients or public were involved in this study design, conduct or analysis.

\section{Exposure and eligibility criteria}

Professional activity and working hours were self-reported using the following questions: 'Are you currently engaged in a professional activity?'; 'What is your usual work schedule?' (day exclusively, rotation with no night work, rotation with night work, night work only). The number of work hours per week was also recorded. Participants not currently engaged in a professional activity were excluded from the present analysis. No other exclusion criteria were applied.

\section{Outcome assessment}

Metabolic syndrome was defined according to the Joint Interim Statement ${ }^{16}$ as the presence of at least three of the following five conditions: high BP (systolic BP $\geq 130 \mathrm{~mm}$ $\mathrm{Hg}$ or diastolic $\mathrm{BP} \geq 85 \mathrm{~mm} \mathrm{Hg}$ or use of antihypertensive medication); visceral obesity (waist circumference $\geq 88 \mathrm{~cm}$ in women or $\geq 102 \mathrm{~cm}$ in men); high triglycerides $(\geq 1.7 \mathrm{mmol} / \mathrm{L}$, or use of fibrates or nicotinic acid); low HDL-cholesterol levels $(<1.30 \mathrm{mmol} / \mathrm{L}$ in women or $<1.03 \mathrm{mmol} / \mathrm{L}$ in men or use of fibrates or nicotinic acid) and high fasting plasma glucose $(\geq 5.6 \mathrm{mmol} / \mathrm{L}$ or use of antidiabetic medication). BP was measured three times on the left arm using an Omron HEM-907 (Matsusaka, Japan) automated oscillometric sphygmomanometer after at least a $10 \mathrm{~min}$ rest in the seated position. The mean of the last two measures was used. Venous blood samples were drawn after an overnight fast to measure the levels of glucose, HDL cholesterol, low HDL-cholesterol and triglycerides. Biological assays were performed at the clinical laboratory of the Lausanne university hospital within 2 hours of blood collection. Index of insulin resistance during fasting was assessed by the homeostatic model assessment of insulin resistance, calculated as the fasting insulin level (in milliunits per millilitre) times the fasting glucose level (in milligrams per litre) divided by 405. Waist circumference was measured two times with a non-stretchable tape over the unclothed abdomen at the mid-point between the lowest rib and the iliac crest. Hip circumference was also measured two times at the greater trochanters. For waist and hip, the mean of the two measurements was used and the waist-to-hip ratio was calculated.

\section{Covariates}

The current socioprofessional category was selfreported by participants. Sociodemographic (age, sex) and lifestyle (smoking habit, alcohol intake, coffee consumption) data were collected by self-administered questionnaires. Educational level was categorised as low (primary), middle (apprenticeship or secondary school) or high (university). Smoking status was categorised as 
never, former or current. Body weight and height were measured with participants standing without shoes in light indoor clothing. Body weight was measured in kilograms to the nearest $0.1 \mathrm{~kg}$ using a Seca scale (Seca, Hamburg, Germany). Height was measured to the nearest $5 \mathrm{~mm}$ using a Seca height gauge (Seca, Hamburg, Germany). Body mass index (BMI) was defined as weight $(\mathrm{kg}) /$ height $^{2}\left(\mathrm{~m}^{2}\right)$. Obesity was defined as BMI $\geq 30 \mathrm{~kg} / \mathrm{m}^{2}$.

Medication use was coded according to the WHO Anatomical Therapeutic Chemical Classification System (http://www.whocc.no/atcddd). Drugs influencing sleep included hypnotics or sedatives (N05C), anxiolytics (N05B) and antipsychotics (N05A). Diabetes was defined as fasting plasma glucose levels $\geq 7.0 \mathrm{mmol} / \mathrm{L}$ or use of antidiabetic medication. ${ }^{17}$ Hypertension was defined as systolic BP $\geq 140 \mathrm{~mm} \mathrm{Hg}$ and/or diastolic BP $\geq 90 \mathrm{~mm} \mathrm{Hg}$, and/or current use of antihypertensive medication.

The presence of a current major depressive disorder was retrospectively assigned according to Diagnostic and Statistical Manual of Mental Disorders, Fourth Edition criteria with information collected at the second and third psychiatric follow-up evaluation using the French translation of the semistructured Diagnostic Interview for Genetic Studies. Cardiovascular disease was defined as previous stroke, heart attack, coronary artery bypass grafting or percutaneous coronary intervention.

Subjective sleep characteristics were determined using the Pittsburgh Sleep Quality Index (PSQI), ${ }^{18}$ the Epworth Sleepiness Scale (ESS $)^{19}$ and the Berlin questionnaire for sleep-disordered breathing (SDB) ${ }^{20}$ Sleep quality was assessed with the PSQI and dichotomised into good/poor sleep quality (score $\leq 5 />5$ ), and excessive daytime sleepiness was defined as an ESS score $>10$ ). A Berlin score $\geq 2$ was defined as indicating a high risk of SDB.

Dietary intake was evaluated using a validated Food Frequency Questionnaire querying the consumption of 97 different food items, including portion size over the previous 4 weeks. The daily total energy intake was obtained as well as the proportion of macronutrients, alcohol and fibres.

Physical activity was evaluated with the physical activity frequency questionnaire (PAFQ) ${ }^{21}$ The questionnaire lists 70 types of physical activity from various domains (eg, occupational, housework, leisure time, sports, etc) and participants indicated the number of days in the past week (0-7) and the duration per day (0-10 hour, in $15 \mathrm{~min}$ increments) for each activity. Energy expenditure corresponds to the sum of all the energy expenditure over 1 week divided by 7 to obtain a mean energy expenditure over a 24-hour period. Sedentary status was defined as spending more than $90 \%$ of daily energy in activities below moderate and high intensity (defined as requiring at least 4 times the basal metabolic rate. The percentage of total energy $>4$ metabolic equivalents was also calculated to quantify moderate and high- intensity physical activity.

\section{Statistical analysis}

Data distribution was graphically assessed using a normal Q-Q plot. Data were presented as number of participants (\%) for categorical variables, mean \pm SD for normal distribution or median and IQR for non-normally distributed continuous variables. Univariate analyses of continuous data were performed using one-way Analyis of Variance (ANOVA) or Kruskal Wallis test follow by Bonferroni's post hoc or Tamhane's T2 as appropriate. Categorical variables were analysed using $\chi^{2}$ test or Fisher's exact test as appropriate. The associations between working schedules (permanent day, day-shift work, night-shift work and permanent night work) and metabolic syndrome (and its subcomponents) were determined using logistic regression analysis. Prior to this, the interaction of sex with the metabolic syndrome and each of its subcomponents was tested. In case of significant interaction, results were presented for both men and women, otherwise results were shown for the whole sample. Each cardiometabolic risk factor was first tested in univariate analysis (crude) then in two models with serial adjustment for potential confounders. Model one was adjusted for age (continuous), educational level (low, middle, high) and sex (except in case of significant sex $\times$ outcome interaction). Model 2: model 1 plus weekly alcohol consumption (continuous), smoking status (never, former, current) and BMI (normal weight, overweight, obese; except for visceral obesity). Model 3: model 2 plus daily total energy expenditure (continuous). Box-Tidwell tests were used to check the assumption of linearity for the logit of each covariate. If the assumption was violated, the square of the covariate was used or the covariate was transformed into categorical variable. To assess collinearity between covariates, a linear regression analysis including all covariates was performed, and the variance inflation factor (VIF) was calculated. A VIF $\leq 5$ was considered as absence of multicollinearity. Results from logistic regression are presented as OR values with 95\% CI. Permanent day workers were considered as the reference group.

All statistical analyses were performed using IBM SPSS Statistics V.26.0 for Macintosh (IBM Corp). Significant results were considered for a two-sided test with $\mathrm{p}<0.05$.

\section{RESULTS \\ Population characteristics}

A total of 2301 participants were engaged in a professional activity at the second follow-up of the CoLaus/PsyCoLaus study. Among them, 1905 worked exclusively during the daytime (permanent day workers), 220 were rotation workers with no night work (day-shift workers), 134 were rotation workers with night work (night-shift workers) and 42 worked exclusively during the night (permanent night workers) (online supplemental figure 1). 
Tables 1 and 2 show the baseline characteristics of the sample according to the four different work schedules. The mean age of the participants was $56.2 \pm 6.9$ years and half of the sample $(50.1 \%)$ were women. The proportions of men/women differed significantly according to work schedule: women were more likely to work in day shift and permanent night shift roles, while men were more likely to do night shift work. Mean BMI and waist circumference were significantly higher in night shift workers and permanent night workers compared with permanent day workers and day shift workers $(\mathrm{p}<0.001)$. Permanent night shift workers were more likely to smoke than other groups, whereas night-shift workers were less sedentary than their counterparts. Lipid levels and blood glucose analysis and sleep parameters in the different work schedule groups are also shown in tables 1 and 2.

\section{Prevalence of metabolic syndrome and its components according to work schedules}

There were significant interactions between sex and work schedule for metabolic syndrome $(p=0.009)$, high triglycerides $(\mathrm{p}=0.043)$ and visceral obesity $(\mathrm{p}=0.047)$, but not for high BP, high glucose and low HDL-cholesterol.

The prevalence of the metabolic syndrome was almost three times higher in men permanent night workers compared with men permanent-day workers; a similar trend was found for the prevalence of visceral obesity and low HDL-cholesterol (table 3). The prevalence of high glucose level in night shift workers and permanent night workers was nearly double that in permanent day workers (table 3).

\section{Association between metabolic syndrome and work schedules by patient sex}

Compared with men permanent day workers, permanent night workers showed a higher risk of metabolic syndrome in univariate analysis (OR 6.48 (95\% CI 2.40 to 17.46); online supplemental table 1). This significant association persisted after adjustment for age, educational level, alcohol consumption, smoking status and daily total energy expenditure (OR 4.45 (95\% CI 1.36 to 14.56)) (figure 1). Conversely, the risk of metabolic syndrome in day shift-workers was lower than that in permanent day workers in crude analysis (OR 0.36 (95\% CI 0.18 to 0.74$)$ ), and after adjustment in models 1 and 2 and 3 (online supplemental table 1). No significant association between work schedule and metabolic syndrome was found for women.

\section{Association of each component of metabolic syndrome with work schedule}

In men, the risk of visceral obesity in permanent night workers was significantly higher than that in permanent day workers, including after adjustment for covariates (table 4). Moreover, the risk of elevated triglyceride levels in permanent night workers was increased in the crude analysis and after adjustment for age, educational level, alcohol consumption, smoking status and BMI (model 2) but was no longer significant in the fully adjusted model 3 (table 4).

In women, night-shift workers showed a higher risk of elevated triglyceride levels, which persisted after multiple adjustments (table 4 ).

\section{DISCUSSION}

In our middle-to-older-aged active general population sample, we found differential associations between permanent night work and the risk of metabolic syndrome for men and women. Indeed, permanent night work was only associated with a higher risk of metabolic syndrome in men but not in women. This association could be mediated by a higher risk of visceral obesity in men. The increased risk of metabolic syndrome is in line with previous studies. ${ }^{22}$ Some studies even showed that the risk for the development of metabolic syndrome and each of its components gradually and independently increase with accumulated years of shift work. ${ }^{23}$ Contrary to other studies, we found no association between permanent night work or night-shift work and metabolic syndrome in women. ${ }^{24}{ }^{25}$ In contrast to the findings on the metabolic syndrome as a whole, for the triglycerides component, we found an increased risk of elevated concentrations among shift workers in women but not in men. This supports previous evidence from Karlsson et al who also reported an elevated triglyceride level among shift workers in 60 -year-old women. ${ }^{26}$

While the mechanisms underlying the observed increased risk of metabolic syndrome in shift or night workers have not been fully elucidated, several explanatory hypotheses can be proposed. First, sleep duration has been suggested to play a key role in the development of metabolic syndrome. A previous meta-analysis found that short sleep duration was significantly associated with a $27 \%$ increase in risk of metabolic syndrome, whereas long sleep duration was not. ${ }^{27}$ Similar results were found in both men and women. In our study, self-reported sleep duration did not differ between the different groups of workers and, therefore, does not explain the increased risk of metabolic syndrome observed in permanent night workers among men. However, we cannot rule out that our findings might have been different if objective sleep duration measures were used because objective and subjective sleep duration can differ significantly. Unfortunately, objective sleep assessment could not be included in our analysis. Moreover, sleep fragmentation or an alteration of sleep structure due to irregular sleep schedule or circadian rhythm misalignment in night workers cannot be excluded and could be a possible explanation for the increased risk of metabolic syndrome. ${ }^{28} 29$

Second, dietary habits could contribute to development of the metabolic syndrome in night or shift workers, but available studies on this subject are scarce. A crosssectional study comparing 98 rotating shift workers to 100 regular day workers demonstrated that total energy intake and contributions of macronutrients did not 


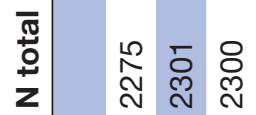

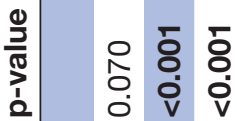

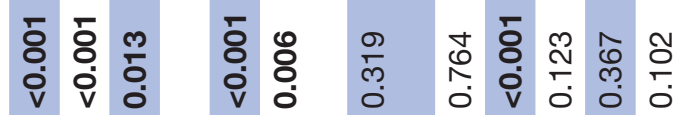

节苔

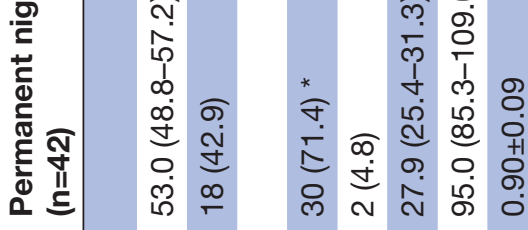

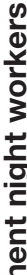

0 ก

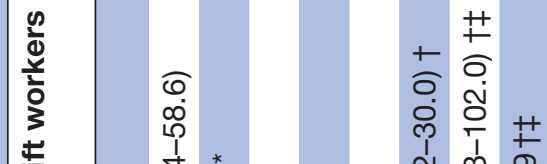

ก)

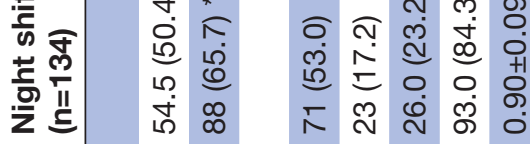

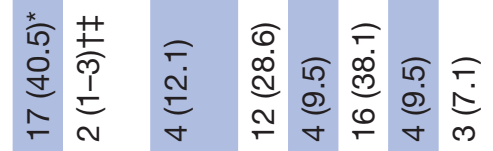

ก. 0 ด

舟旁

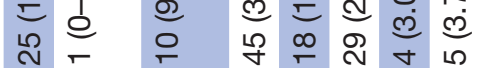

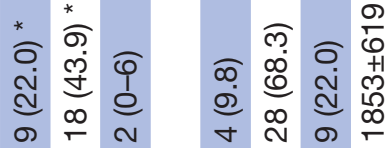

क ส สุ ส

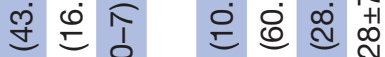

กิ ลั

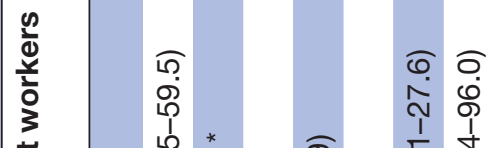

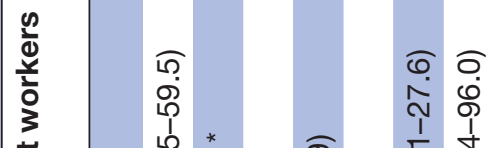

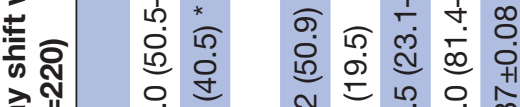

ọ

ธก โิก

\section{芒

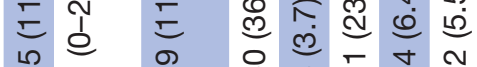

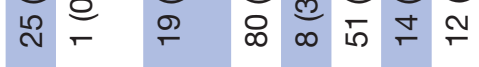

क $\widehat{\sigma}$

过 啇

$œ$ \&

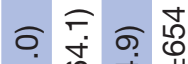

E $\stackrel{a}{\mathbb{2}} \frac{1}{0}$

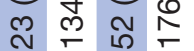

ब1

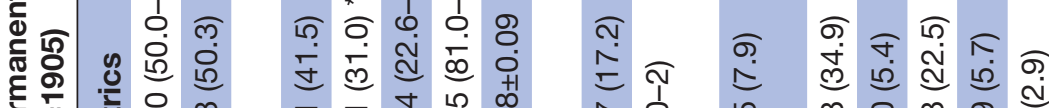

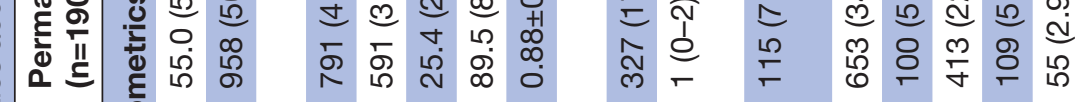

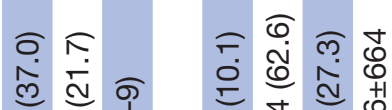

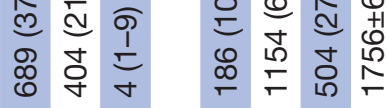

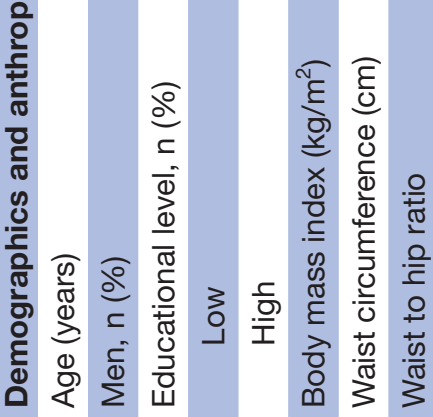

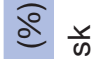

(1)

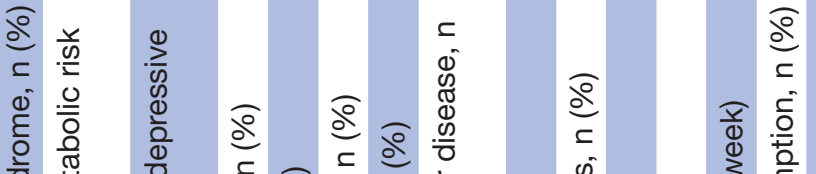

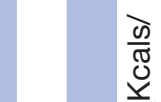




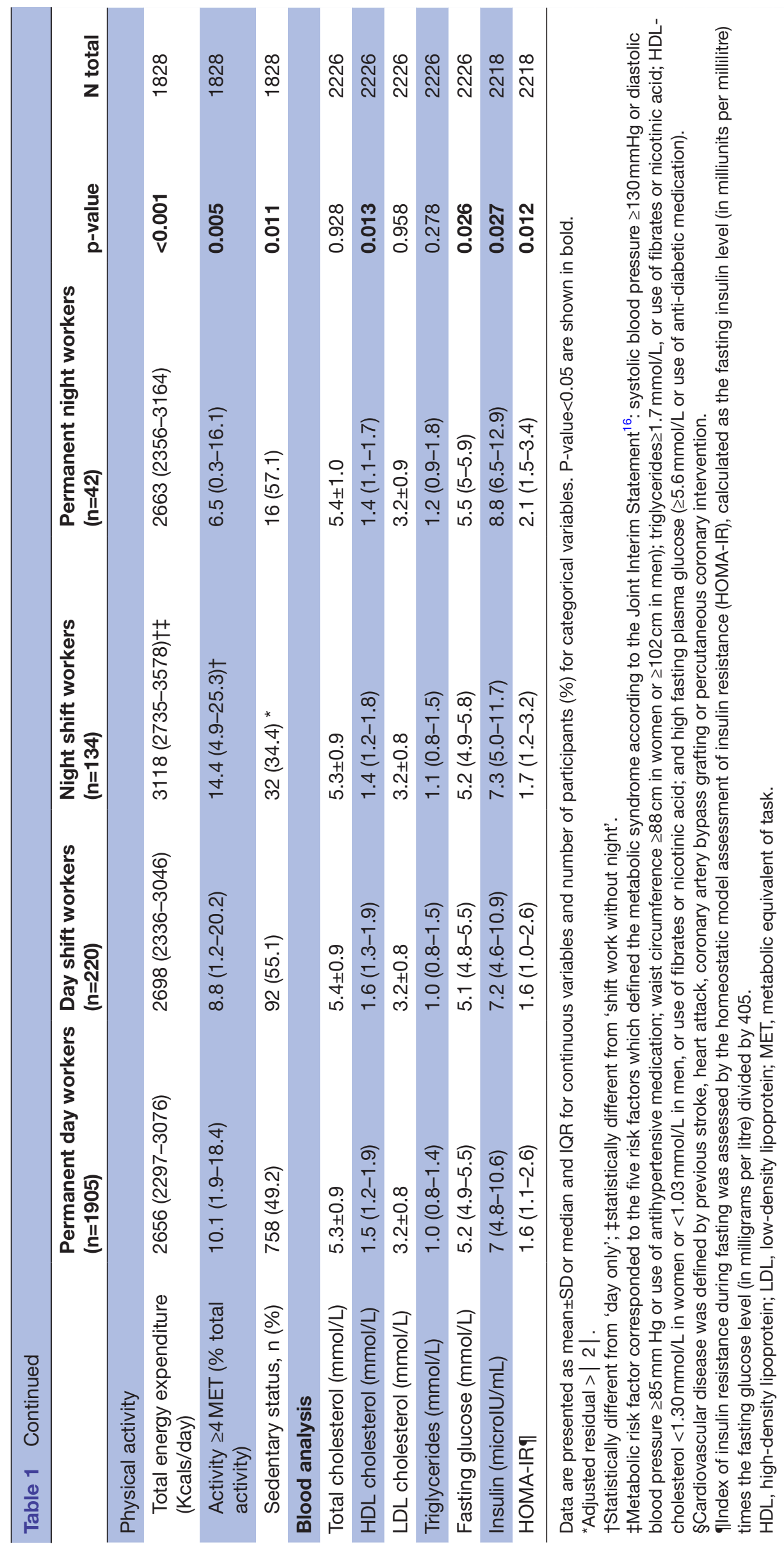


Table 2 Working and sleep characteristics according to work schedules

\begin{tabular}{|c|c|c|c|c|c|c|}
\hline & $\begin{array}{l}\text { Permanent day } \\
\text { workers }(n=1905)\end{array}$ & $\begin{array}{l}\text { Day shift } \\
\text { workers } \\
(n=220)\end{array}$ & $\begin{array}{l}\text { Night shift } \\
\text { workers } \\
(n=134)\end{array}$ & $\begin{array}{l}\text { Permanent night } \\
\text { workers }(n=42)\end{array}$ & $p$-value & $\mathbf{N}$ total \\
\hline \multicolumn{7}{|c|}{ Working characteristics } \\
\hline $\begin{array}{l}\text { Number of working } \\
\text { hours/week }\end{array}$ & $38.0 \pm 14.7$ & $38.7 \pm 15.2$ & $43.1 \pm 18.1$ & $38.0 \pm 15.2$ & 0.260 & 2285 \\
\hline Work time, $\mathrm{n}(\%)$ & & & & & 0.397 & 2258 \\
\hline$<50 \%$ & $304(16.2)$ & $33(15.4)$ & $18(14.0)$ & $3(7.1)$ & & \\
\hline \multicolumn{5}{|c|}{ Example of physical intensity at work, $n$ (\%) } & $<0.001$ & 2135 \\
\hline $\begin{array}{l}\text { Sedentary (sitting/ } \\
\text { driving) }\end{array}$ & $1409(79.5)$ & $105(51.2)$ & $66(55.0)$ & $14(37.8)$ & & \\
\hline $\begin{array}{l}\text { Pushing } \\
\text { wheelbarrow }\end{array}$ & $283(16.0)$ & $81(39.5)$ & $40(33.3)$ & $16(43.2)$ & & \\
\hline \multicolumn{7}{|l|}{ Sleep and vigilance } \\
\hline $\begin{array}{l}\text { Epworth Sleepiness } \\
\text { Scale score }\end{array}$ & $6(4-8)$ & $5(3-8)$ & $6(4-9)$ & $5(3-8)$ & 0.623 & 1786 \\
\hline $\begin{array}{l}\text { Excessive daytime } \\
\text { sleepiness, } n(\%)^{*}\end{array}$ & $182(12.1)$ & $20(12.6)$ & $14(14.0)$ & $3(11.1)$ & 0.950 & 1786 \\
\hline $\begin{array}{l}\text { Poor sleep quality, } \\
\mathrm{n}(\%) \dagger\end{array}$ & $415(31.5)$ & $46(37.4)$ & $27(32.1)$ & 7 (35.0) & 0.600 & 1542 \\
\hline $\begin{array}{l}\text { High risk of SDB, } n \\
(\%) \ddagger\end{array}$ & 321 (21.3) & $34(21.0)$ & $29(28.4)$ & 8 (27.6) & 0.323 & 1800 \\
\hline $\begin{array}{l}\text { Self-reported total } \\
\text { sleep time (hour) }\end{array}$ & $6.9 \pm 1.0$ & $6.8 \pm 0.9$ & $6.9 \pm 1.0$ & $7.1 \pm 1.3$ & 0.507 & 1542 \\
\hline
\end{tabular}

Data are presented as mean \pm SD or median and IQR for continuous variables and number of participants (\%) for categorical variables.

$P$-value $<0.05$ are shown in bold.

${ }^{*}$ Excessive daytime sleepiness was defined by an Epworth Sleepiness Scale score $>10$.

†Poor sleep quality was defined by a Pittsburgh Sleep Quality Index score $>5$.

łHigh risk of SDB was defined by a Berlin score $>2$.

$\mathrm{SDB}$, sleep-disordered breathing.

differ between the two groups, except for saturated lipids $(+10 \%$ in shift workers $) .{ }^{30}$ However, meal distribution was different in the two groups. Similar to other studies, ${ }^{31} 32$ we failed to demonstrate a difference in food intake and macronutrients components between night shift workers or permanent night workers compared with permanent day workers. Available data from our study mean that, unfortunately, we cannot rule out the possibility that night shift workers may have had a different circadian distribution of food intake rather than an increase in total daily intake. ${ }^{33}$

Third, circadian rhythm desynchronisation could be a major contributor to the increased risk of metabolic syndrome among night and shift workers. Still, the underlying pathophysiological mechanisms of this association remain poorly understood. Some animal studies suggested that reduced melatonin production, due to circadian rhythm disruption, could be associated with a higher rate of metabolic syndrome. ${ }^{34}$ Furthermore, Fonken et al hypothesised that exposure to light at night altered circadian organisation and affected metabolic parameters in mice. ${ }^{35}$ Their results emphasised that even weak night lighting (5lux) is sufficient to desynchronise food consumption and physical activity rhythms, which could explain the observed metabolic disorders. ${ }^{34}$ In humans, Corbalan-Tutau et al reported a reduced daily amplitude in melatonin and cortisol circadian patterns associated with metabolic disturbances in women. ${ }^{36}$ Unfortunately, we did not measure melatonin and cortisol to confirm these findings in our sample.

With regards to physical activity, we surprisingly found that night shift workers were more active than day shift workers and permanent day workers. This may be due to greater opportunities to perform a physical activity compared with other diurnal workers or to more physically active work among night shift workers, although this should be interpreted with caution due to limited agreement between estimates of activity obtained by PAFQ and those obtained from accelerometers. ${ }^{37}$

Finally, the higher risk of metabolic syndrome we observed in night shift workers may be explained by a vitamin D deficiency. ${ }^{38}$ It has been shown that high levels 
Table 3 Prevalence of metabolic syndrome and its subcomponents according to work schedule

\begin{tabular}{|c|c|c|c|c|c|}
\hline & $\begin{array}{l}\text { Permanent day workers } \\
(n=1905)\end{array}$ & $\begin{array}{l}\text { Day shift workers } \\
(n=220)\end{array}$ & $\begin{array}{l}\text { Night shift workers } \\
(n=134)\end{array}$ & $\begin{array}{l}\text { Permanent night workers } \\
(\mathrm{n}=42)\end{array}$ & p-value \\
\hline \multicolumn{6}{|c|}{ Metabolic syndrome } \\
\hline Women & $101(10.7)$ & $16(12.2)$ & $8(17.4)$ & $5(20.8)$ & 0.225 \\
\hline High BP & $826(43.4)$ & $91(41.4)$ & $64(47.8)$ & $23(54.8)$ & 0.313 \\
\hline Men & $243(26.2)$ & $25(29.1)$ & $18(21.2)$ & $11(61.1)$ & 0.006 \\
\hline Women & $86(9.5)$ & $16(12.3)$ & 9 (19.6) & $3(12.5)$ & 0.183 \\
\hline $\begin{array}{l}\text { Low HDL- } \\
\text { cholesterol }\end{array}$ & 201 (10.9) & $19(8.8)$ & $10(7.6)$ & $9(21.4)$ & 0.064 \\
\hline
\end{tabular}

Data are presented as $\mathrm{n}(\%)$.

Where there was an interaction of outcome*sex, results are presented separately for men and women, otherwise for the whole cohort. $\mathrm{BP}$, blood pressure; HDL, high-density lipoprotein.

of vitamin $\mathrm{D}$ among middle-aged and elderly populations are associated with a substantial decrease in cardiovascular disease, type 2 diabetes and metabolic syndrome. ${ }^{39}$ Although we did not measure the vitamin D levels in our different groups of workers, we can hypothesise that permanent night workers have lower exposure to sunlight and may, therefore, be at higher risk of vitamin D deficiency. ${ }^{40}$

In our study, among the components of the metabolic syndrome, an elevated risk of visceral obesity was found in men permanent night workers. This finding is consistent with a recent meta-analysis, which found that shift workers had a higher frequency of abdominal obesity than other obesity types and permanent night workers

\section{Metabolic syndrome}

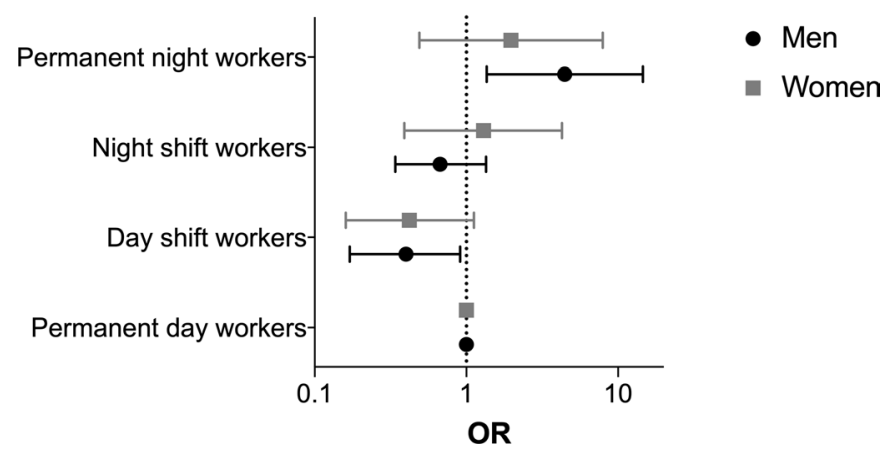

Figure 1 Multivariable-adjusted risk of metabolic syndrome according to work schedule and sex. Data are presented on a logarithmic scale and were analysed using multivariable logistic regression with adjustment for age, educational level, weekly alcohol consumption, smoking status and daily total energy expenditure (model 3). demonstrated a $29 \%$ higher risk of central obesity than rotating shift workers. ${ }^{41}$

The main strength of the present study is its large population-based sample of middle-to-older-aged workers with a precise and extensive assessment of cardiometabolic phenotypes. Indeed, previous studies were mainly performed in younger specific populations of workers or, in particular, sectors of activity, such as public health and emergency, which limit the generalisability to other types of shift or night work. In addition, most studies have assessed the risk of metabolic syndrome in shift workers compared with day workers, but few studies have differentiated between shift workers, permanent night workers and shift workers with and without night work.

There are also some limitations that need to be mentioned. First, this study had a cross-sectional design, which did not allow to assess causality but only crosssectional associations that remain to be confirmed in prospective studies. Because the primary aim of the CoLaus|PsyCoLaus study was not to evaluate the impact of shift work, the questions related to shift work were only asked at the follow-up 2 (2014-2017), preventing us to investigate longitudinal associations. Moreover, no precise characterisation of workstations and work rhythms (hourly amplitude, direction of rotation, duration of rotations and duration of exposition) were performed. Likewise, it would have been interesting to have any information regarding food intakes or other habits in the workplaces. Second, a 'healthy worker effect' with a selection of 'night shift tolerant' workers cannot be ruled out given the older age of our sample. Third, our sample of permanent night workers is rather small but we may assume that workers move away from night shift work with advancing age due to poorer tolerability and less family 


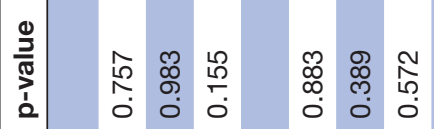

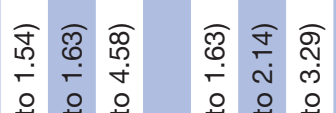

每

选

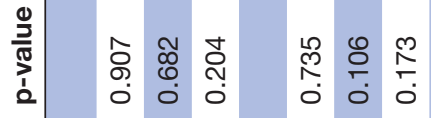

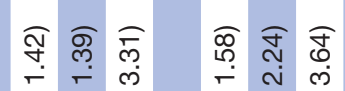

ง นั้

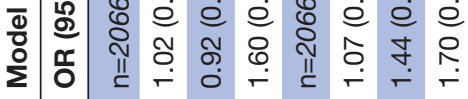

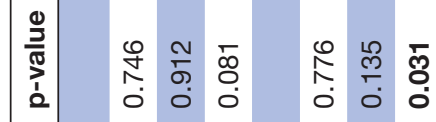

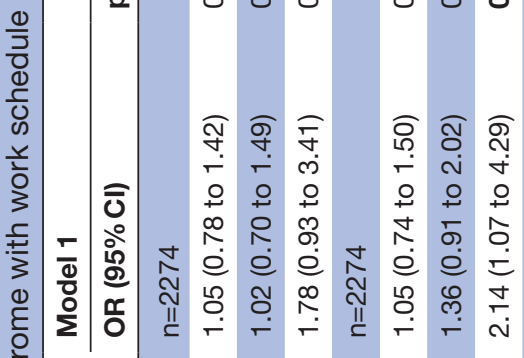

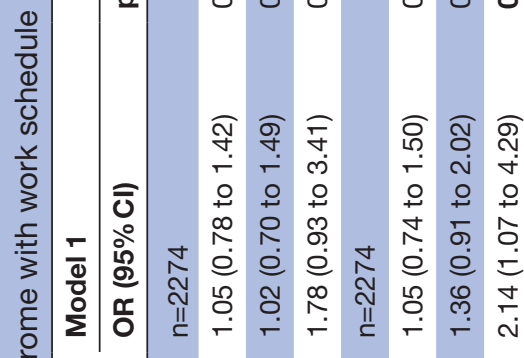

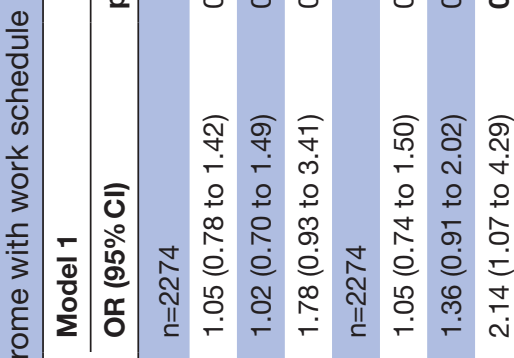

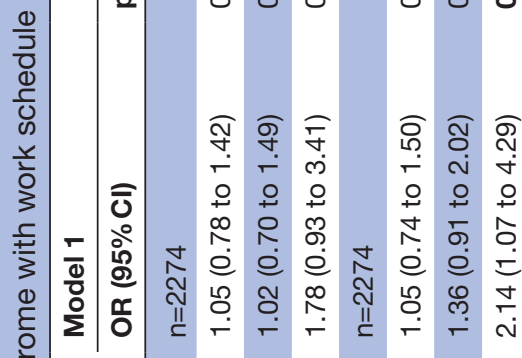

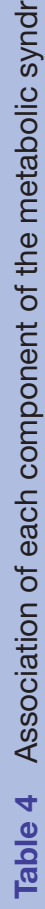

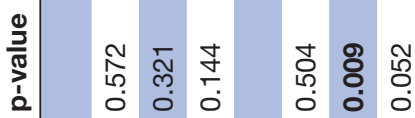

उ)

उ

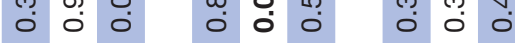

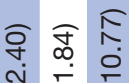

ก

ก กิ

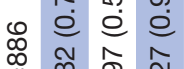

II

o
일
อ ¿

กิ

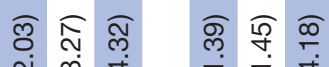

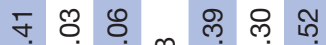

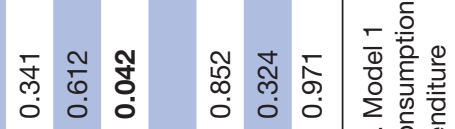

흥 응 $\frac{0}{8}$

ส

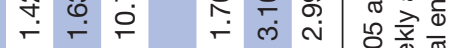

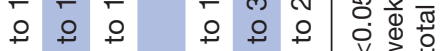

饮 莳

৪ 仓े

III

0

능 즐

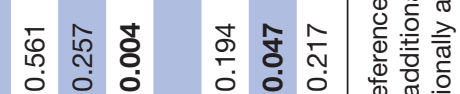

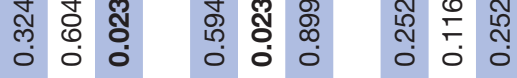

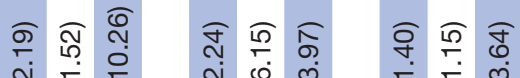

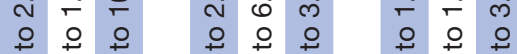

र व

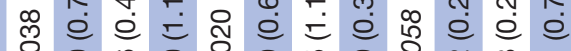

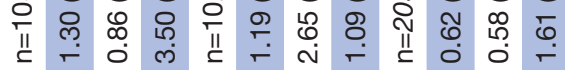

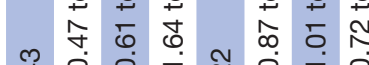

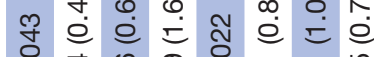

II

क्ष.

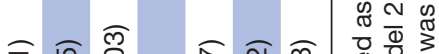

官

ए人)

하을 을

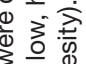

in $\frac{\varrho}{\bar{\nabla}} \circ$

늫

m

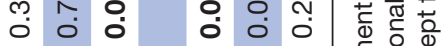

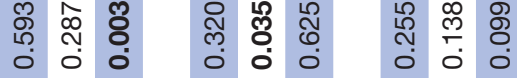

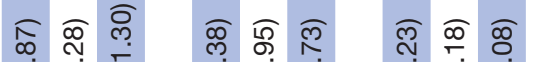

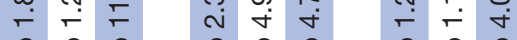

웅ㅇ 우요 우웅

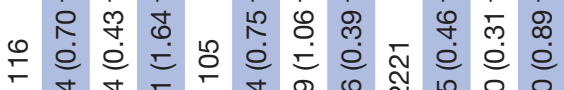

III

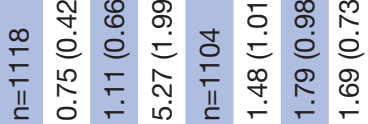

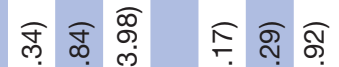

है잉

$\therefore$ 용

ले

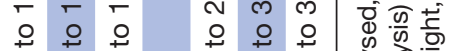

ง 0 \%

प्रे

高 稢

हे ऐे

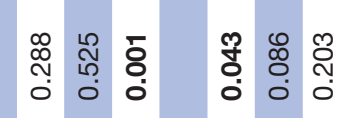

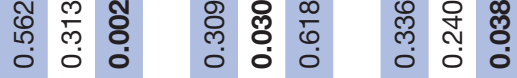

등 훙

它

훈 $\times \sum_{0}$

তิ宀 홍

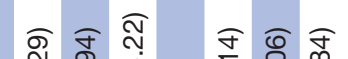

응 응

त ले

우요 우 우 우

ช ร

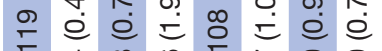

III

J)

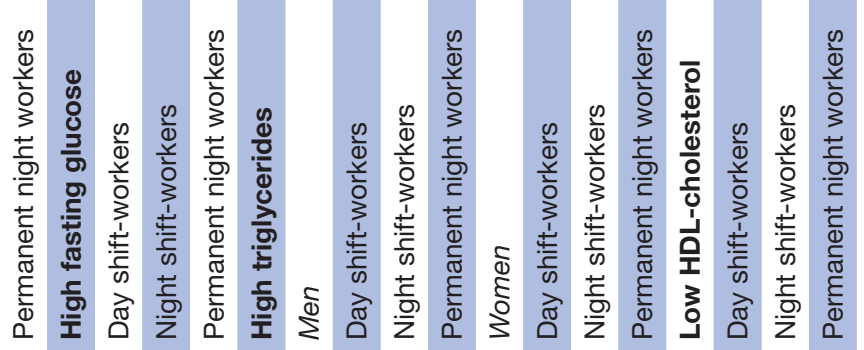


constraints. Fourth, there were some missing data on selfreported sleep habits and diet parameters and, despite the use of validated questionnaires, declaration bias remains possible. Similarly, only self-reported physical activity was assessed in this study and it would have been interesting to have objective measures of physical activity and sleep to more accurately investigate their influence.

\section{CONCLUSION}

Only men permanent night workers were at increased risk of metabolic syndrome compared with permanent day workers, and this association persisted after adjustment for sociodemographic confounders and daily total energy expenditure. From a clinical point of view, we advise monitor of not only BMI but also visceral obesity, particularly in men permanent night workers. Further prospective studies are needed to confirm theses cross-sectional results and elucidate the underline mechanisms.

\section{Author affiliations}

${ }^{1}$ Center of Investigation and Research on Sleep (CIRS), University Hospital of Lausanne (CHUV) and University of Lausanne (UNIL), Lausanne, Switzerland ${ }^{2}$ Department of Medicine, Internal Medicine, CHUV and University of Lausanne, Lausanne, Switzerland

${ }^{3}$ Department of Psychiatry, CHUV and University of Lausanne, Lausanne, Switzerland

${ }^{4}$ Centre du sommeil et de la vigilance, Hôtel Dieu, APHP, Paris, France ${ }^{5}$ EA 7330 VIFASOM, Sommeil-Vigilance-Fatigue et Santé Publique, Université Paris Descartes, Sorbonne Paris Cité, Paris, France

Correction notice This article has been corrected since it was first published. The lincese type has been updated to CC BY.

Twitter Pedro Marques-Vidal @PMarquesVidal

Acknowledgements The authors thank Prof. Mehdi Tafti, Prof. Vincent Mooser, Daniela Andries and Nadia Tobback for their important contribution to the HypnoLaus and CoLausIPsyCoLaus Cohorts, the Lausanne population who volunteered to participate in the CoLaus|PsyCoLaus and HypnoLaus studies, as well as the whole team of CoLaus|PsyCoLaus.

Contributors VB, MB, PMV, MP and RH designed the study. JH-R, PM-V, M-PS, $M P$ and $\mathrm{RH}$ collected the data. MB performed the statistical analysis. VB, MB, GS, JH-R, PMV, M-PS, MP, DL and RH interpreted the data. VB and MB wrote the first draft of the manuscript and GS, JH-R, PMV, M-PS, MP, DL and RH critically reviewed the manuscript. All authors undertake to give final approval of the version to be published and agree to be accountable for all aspects of the work. VB is the guarantor of this work and, as such, had full access to all the data in the study and takes responsibility for the integrity of the data and the accuracy of the data analysis.

Funding The HypnoLaus and the CoLaus/ PsyCoLaus studies were supported by research grants from GlaxoSmithKline ('not applicable'), the Faculty of Biology and Medicine of Lausanne ('not applicable'), the Swiss National Science Foundation (grants 3200B0-105993, 3200B0-118308, 33CSC0-122661, 33CS30-139468 and 33CS30-148401), Leenaards Foundation ('not applicable'), and Vaud Pulmonary League ('not applicable').

Competing interests None declared.

Patient consent for publication Consent obtained directly from patient(s)

Ethics approval This study involves human participants and was approved by the Institutional Ethics Committee of the University of Lausanne (decision reference 33/09) and written inform consent was obtained from all subjects. A copy of the written Inform Consent form was handed out to the subjects. A further copy was provided for the archives of the study in the Center for Investigation and Research in Sleep (CIRS, Lausanne University Hospital, Switzerland). Participants gave informed consent to participate in the study before taking part.
Provenance and peer review Not commissioned; externally peer reviewed.

Data availability statement Data may be obtained from a third party and are not publicly available. Due to the sensitivity of the data and the lack of consent for online posting, individual data cannot be made accessible. Only metadata will be made available in digital repositories. Metadata requests can also be made via the study website: www.colaus-psycolaus.ch.

Supplemental material This content has been supplied by the author(s). It has not been vetted by BMJ Publishing Group Limited (BMJ) and may not have been peer-reviewed. Any opinions or recommendations discussed are solely those of the author(s) and are not endorsed by BMJ. BMJ disclaims all liability and responsibility arising from any reliance placed on the content. Where the content includes any translated material, BMJ does not warrant the accuracy and reliability of the translations (including but not limited to local regulations, clinical guidelines, terminology, drug names and drug dosages), and is not responsible for any error and/or omissions arising from translation and adaptation or otherwise.

Open access This is an open access article distributed in accordance with the Creative Commons Attribution 4.0 Unported (CC BY 4.0) license, which permits others to copy, redistribute, remix, transform and build upon this work for any purpose, provided the original work is properly cited, a link to the licence is given, and indication of whether changes were made. See: https://creativecommons.org/ licenses/by/4.0/.

\section{ORCID iDs}

Mathieu Berger http://orcid.org/0000-0002-6415-7694

Geoffroy Solelhac http://orcid.org/0000-0002-7135-133X

\section{REFERENCES}

1 Nappo N. Is there an association between working conditions and health? An analysis of the sixth European working conditions survey data. PLoS One 2019;14:e0211294

2 Puttonen S, Viitasalo K, Härmä M. Effect of shiftwork on systemic markers of inflammation. Chronobiol Int 2011;28:528-35.

3 Sallinen M, Kecklund G. Shift work, sleep, and sleepiness differences between shift schedules and systems. Scand J Work Environ Health 2010;36:121-33.

4 Knutson KL, Spiegel K, Penev P, et al. The metabolic consequences of sleep deprivation. Sleep Med Rev 2007;11:163-78.

5 Faraut B, Bayon V, Léger D. Neuroendocrine, immune and oxidative stress in shift workers. Sleep Med Rev 2013;17:433-44.

6 Kecklund G, Axelsson J. Health consequences of shift work and insufficient sleep. BMJ 2016;355:i5210.

7 Drake CL, Roehrs T, Richardson G, et al. Shift work sleep disorder: prevalence and consequences beyond that of symptomatic day workers. Sleep 2004;27:1453-62.

8 Morikawa $\mathrm{Y}$, Nakagawa $\mathrm{H}$, Miura $\mathrm{K}$, et al. Effect of shift work on body mass index and metabolic parameters. Scand J Work Environ Health 2007;33:45-50.

9 Wang D, Ruan W, Chen Z, et al. Shift work and risk of cardiovascular disease morbidity and mortality: a dose-response meta-analysis of cohort studies. Eur J Prev Cardiol 2018;25:1293-302.

10 Wu SH, Hui WS, Liu Z, SH W, SC H, et al. Metabolic syndrome and all-cause mortality: a meta-analysis of prospective cohort studies. Eur J Epidemiol 2010;25:375-84.

11 Galassi A, Reynolds K, He J. Metabolic syndrome and risk of cardiovascular disease: a meta-analysis. Am J Med 2006;119:812-9.

12 Karlsson B, Knutsson A, Lindahl B. Is there an association between shift work and having a metabolic syndrome? Results from a population based study of 27485 people. Occup Environ Med 2001:58:747-52.

13 Violanti JM, Burchfiel CM, Hartley TA, et al. Atypical work hours and metabolic syndrome among police officers. Arch Environ Occup Health 2009;64:194-201.

14 Canuto R, Garcez AS, Olinto MTA. Metabolic syndrome and shift work: a systematic review. Sleep Med Rev 2013;17:425-31.

15 Firmann M, Mayor V, Vidal PM, et al. The CoLaus study: a population-based study to investigate the epidemiology and genetic determinants of cardiovascular risk factors and metabolic syndrome. BMC Cardiovasc Disord 2008;8:6.

16 Alberti KGMM, Eckel RH, Grundy SM, et al. Harmonizing the metabolic syndrome: a joint interim statement of the International diabetes Federation Task force on epidemiology and prevention; National heart, lung, and blood Institute; American heart association; world heart Federation; international atherosclerosis Society; 
and international association for the study of obesity. Circulation 2009:120:1640-5.

17 American Diabetes Association. Diagnosis and classification of diabetes mellitus. Diabetes Care 2014;37(Suppl 1):S81-90.

18 Buysse DJ, Reynolds CF, Monk TH, et al. The Pittsburgh sleep quality index: a new instrument for psychiatric practice and research. Psychiatry Res 1989;28:193-213.

19 Johns MW. A new method for measuring daytime sleepiness: the Epworth Sleepiness scale. Sleep 1991;14:540-5.

20 Netzer NC, Stoohs RA, Netzer CM, et al. Using the Berlin questionnaire to identify patients at risk for the sleep apnea syndrome. Ann Intern Med 1999;131:485-91.

21 Bernstein M, Sloutskis D, Kumanyika S, et al. Data-based approach for developing a physical activity frequency questionnaire. $\mathrm{Am} \mathrm{J}$ Epidemiol 1998;147:147-54.

22 Wang F, Zhang L, Zhang Y, et al. Meta-analysis on night shift work and risk of metabolic syndrome. Obes Rev 2014;15:709-20.

23 De Bacquer D, Van Risseghem M, Clays E, et al. Rotating shift work and the metabolic syndrome: a prospective study. Int J Epidemiol 2009;38:848-54.

24 Lim YC, Hoe VCW, Darus A, et al. Association between night-shift work, sleep quality and metabolic syndrome. Occup Environ Med 2018;75:716-23.

25 Guo Y, Rong Y, Huang X, et al. Shift work and the relationship with metabolic syndrome in Chinese aged workers. PLoS One 2015;10:e0120632.

26 Karlsson B, Knutsson A, Lindahl B. Is there an association between shift work and having a metabolic syndrome? Results from a population based study of 27,485 people. Occup Environ Med 2001;58:747-52.

$27 \mathrm{Xi} \mathrm{B}, \mathrm{He} \mathrm{D}$, Zhang M, et al. Short sleep duration predicts risk of metabolic syndrome: a systematic review and meta-analysis. Sleep Med Rev 2014;18:293-7.

28 Stamatakis KA, Punjabi NM. Effects of sleep fragmentation on glucose metabolism in normal subjects. Chest 2010;137:95-101.

29 Tasali E, Leproult R, Ehrmann DA, et al. Slow-wave sleep and the risk of type 2 diabetes in humans. Proc Natl Acad Sci U S A 2008;105:1044-9.
30 Esquirol Y, Bongard V, Mabile L, et al. Shift work and metabolic syndrome: respective impacts of job strain, physical activity, and dietary rhythms. Chronobiol Int 2009;26:544-59.

31 de Assis MAA, Kupek E, Nahas MV, et al. Food intake and circadian rhythms in shift workers with a high workload. Appetite 2003;40:175-83.

32 Morikawa Y, Miura K, Sasaki S, et al. Evaluation of the effects of shift work on nutrient intake: a cross-sectional study. J Occup Health 2008;50:270-8.

33 Molzof HE, Wirth MD, Burch JB, et al. The impact of meal timing on cardiometabolic syndrome indicators in shift workers. Chronobiol Int 2017;34:337-48.

34 Fonken LK, Workman JL, Walton JC, et al. Light at night increases body mass by shifting the time of food intake. Proc Natl Acad Sci U S A 2010;107:18664-9.

35 Fonken LK, Nelson RJ. The effects of light at night on circadian clocks and metabolism. Endocr Rev 2014;35:648-70.

36 Corbalán-Tutau D, Madrid JA, Nicolás F, et al. Daily profile in two circadian markers "melatonin and cortisol" and associations with metabolic syndrome components. Physiol Behav 2014;123:231-5.

37 Verhoog S, Gubelmann C, Guessous I, et al. Comparison of the physical activity frequency questionnaire (PAFQ) with accelerometry in a middle-aged and elderly population: the CoLaus study. Maturitas 2019;129:68-75.

38 Ju SY, Jeong HS, Kim DH. Blood vitamin D status and metabolic syndrome in the general adult population: a dose-response metaanalysis. J Clin Endocrinol Metab 2014;99:1053-63.

39 Parker J, Hashmi O, Dutton D, et al. Levels of vitamin D and cardiometabolic disorders: systematic review and meta-analysis. Maturitas 2010;65:225-36.

40 Daugaard S, Garde AH, Hansen Åse M, et al. Indoor, outdoor, and night work and blood concentrations of vitamin $\mathrm{D}$ and parathyroid hormone. Scand J Work Environ Health 2018;44:647-57.

41 Sun M, Feng W, Wang F, et al. Meta-analysis on shift work and risks of specific obesity types. Obes Rev 2018;19:28-40. 